\title{
Unsubstituted pyrido[3,4-d]pyridazine as an electron- deficient azadiene in [4+2] cycloaddition reactions: a short route to $g$-fused isoquinolines
}

\author{
Esam Abdel-Rehem and Norbert Haider* \\ Institute of Pharmaceutical Chemistry, University of Vienna Althanstraße 14, A-1090 Vienna, \\ Austria \\ E-mail: norbert.haider@univie.ac.at
}

\section{Dedicated with best wishes to Professor Fritz Sauter on the occasion of his $\mathbf{7 0}^{\text {th }}$ birthday (received 11 Nov 00; accepted 28 Oct 01; published on the web 05 Nov 01)}

\begin{abstract}
Pyrido[3,4- $d$ ]pyridazine was shown to undergo thermally induced Diels-Alder reactions (inverse electron-demand) with enamines as electron-rich dienophiles, yielding isoquinoline derivatives. The regiochemistry of the cycloaddition was investigated.
\end{abstract}

Keywords: Pyrido[3,4-d]pyridazine, Diels-Alder reaction with inverse electron-demand, [4+2] cycloaddition, g-fused isoquinoline

\section{Introduction}

In many cases, ring transformation reactions can offer an elegant and efficient access to monoand polycyclic systems, which would be available by conventional assembly only via multi-step procedures. In this context, the inverse-electron-demand Diels-Alder reaction of $\pi$-deficient hetarenes with electron-rich dienophiles has been proven to be of particular value. Whereas the behavior of monocyclic tetrazines, triazines, and diazines in this reaction type has been extensively studied, ${ }^{1-5}$ condensed $\pi$-deficient heteroaromatic compounds have been employed less frequently as starting materials in such cyclo-addition reactions. In recent contributions from our laboratory, the utilization of various fused pyridazines for the construction of higherannulated systems by means of the "inverse" Diels-Alder reaction has been reported. ${ }^{6-14}$ It could be demonstrated that the annulation of a $\pi$-electron-poor ring onto the 1,2-diazine system leads to an activation of this azadiene structure towards electron-rich dienophiles (such as enamines or ketene aminals) in a similar fashion as it can be effected by introduction of one or more electronwithdrawing substituents. So far, however, only two examples of fused pyridazines without any substituents, participating in "inverse" Diels-Alder reactions, are known: Gruseck and Heuschmann ${ }^{15}$ succeeded in the conversion of phthalazine into naphthalene derivatives, using extremely reactive dienophiles with a 2-methyleneimidazolidine structure and more recently, the 
ring transformation of unsubstituted pyrido[2,3-d]pyridazine ("5-azaphthalazine") into various quinoline derivatives was reported by us. ${ }^{11}$ In the course of our studies in this field, we now investigated also the behavior of the isomeric parent system, pyrido[3,4-d]pyridazine (1) ("6azaphthalazine"), towards simple enamines derived from cyclic ketones as dienophilic reagents, and the utility of such cycloaddition reactions for the synthesis of a new type of cycloalkenefused isoquinolines.

\section{Results and Discussion}

The experimental conditions for the reaction of compound 1 with cyclic enamines of different ring size were chosen in analogy to the previously reported cycloaddition reactions of pyrido[2,3-d]pyridazine with the same reagents, ${ }^{11}$ i.e. heating of the hetarene with an excess of enamine in 1,4-dioxane under an argon atmosphere. Not surprisingly, the slightly lower LUMO energy of 1, compared to that of its isomer $(-1.215 \mathrm{eV}$ for $\mathbf{1},-1.122 \mathrm{eV}$ for pyrido[2,3d]pyridazine, calculated with the AM1 method $^{16}$ ) is reflected by a noticeably shorter time required for complete consumption of the starting material.

Thus, when 1-pyrrolidino-1-cyclopentene was used as the dienophile, compound $\mathbf{1}$ was completely consumed after 4 hours of refluxing, compared to 20 hours in the case of pyrido[2,3d]pyridazine. ${ }^{11}$ According to ${ }^{1} \mathrm{H}-\mathrm{NMR}$, the product obtained after evaporation of all volatile components consisted of a 7:1 mixture of two isomeric cyclopentane-fused dihydroisoquinolines, still bearing the pyrrolidinyl moiety, together with a small amount of the corresponding aromatic isoquinoline 2. In order to complete the rearomatization step, the crude mixture was refluxed in toluene in the presence of trifluoroacetic acid (conditions which had been used previously for similar reactions ${ }^{6,711}$ ), which smoothly effected the elimination of pyrrolidine from either isomeric dihydro intermediate and afforded compound 2 as a single product in $47 \%$ overall yield (Scheme 1). 


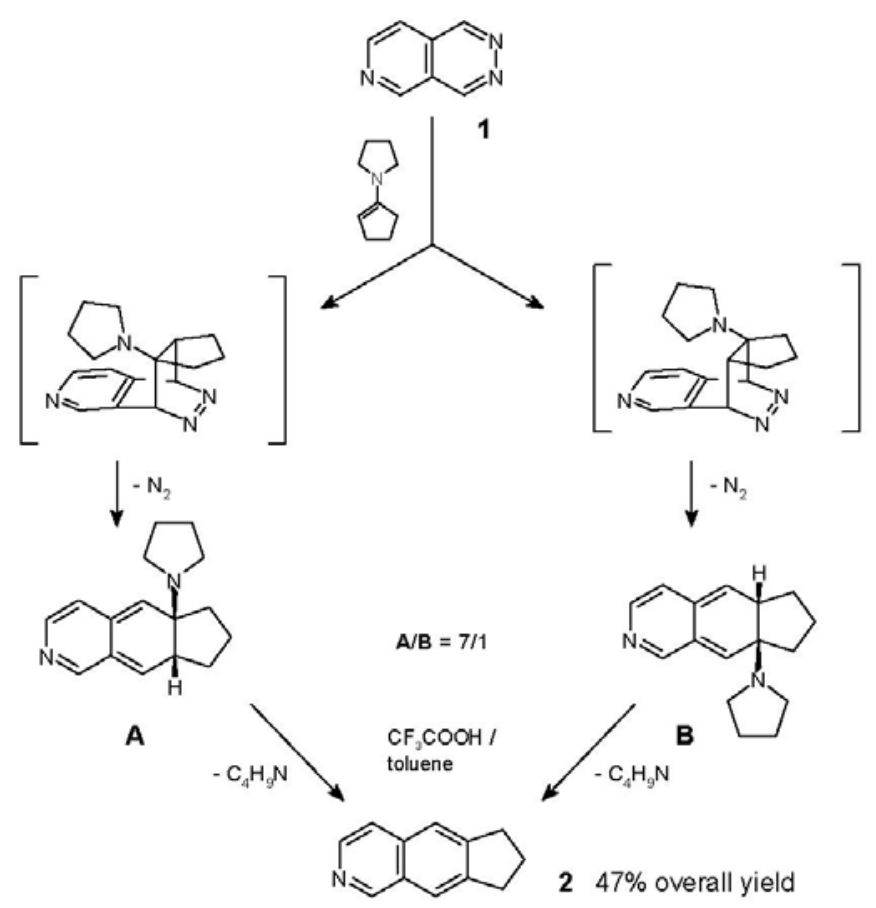

\section{Scheme 1}

In contrast to this two-step ring transformation $\mathbf{1} \rightarrow \mathbf{A} / \mathbf{B} \rightarrow 2$, employment of six-, seven-, and eight-membered cyclic enamines directly leads to the cycloalkene-fused aromatic isoquinolines 3-5 by spontaneous elimination of pyrrolidine from the presumable primary reaction products of type $\mathbf{A} / \mathbf{B}$. In accordance with previous findings, ${ }^{11,14,17,18}$ the enamines derived from cyclohexanone and cyclooctanone turned out to be significantly less reactive, requiring longer reaction times ( 7 days) than the seven-membered analog which effected completion of the cycloaddition in even shorter time ( 0.5 hours) than the five-membered reagent ( 4 hours, see above). After chromatography, the novel $g$-fused isoquinolines were isolated as solids $(3,4)$ or as an oil (5) in yields between 33 and 56\%. Taking into account the convenient availability of the starting material 1, ${ }^{19-21}$ this method offers a short and easy access to these hitherto unknown isoquinolines ${ }^{22}$ bearing a cycloalkene scaffold of variable ring size.

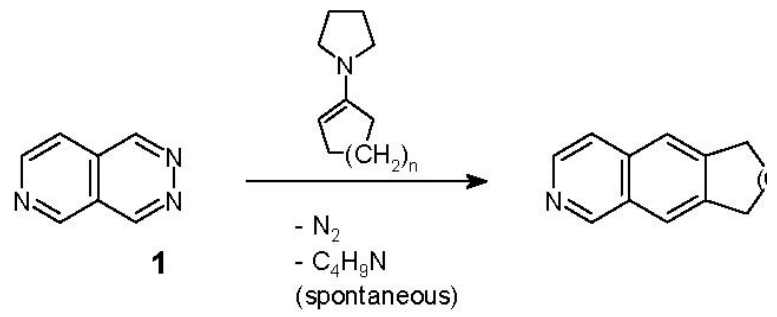

\section{Scheme 2}

In order to gain some insight into the regiochemistry of the cycloaddition reaction of the pyridopyridazine 1 with enamines, the initial reaction mixture obtained after refluxing of 1 with 1-pyrrolidino-1-cyclopentene was examined more closely, as in this case the two isomeric cycloadducts $\mathbf{A}$ and $\mathbf{B}$ are still present (see above). We succeeded in the isolation of the major 
isomer $\mathbf{A}$ by means of medium-pressure liquid chromatography, and the structure of this compound could be established unambiguously by NOE difference spectroscopy.

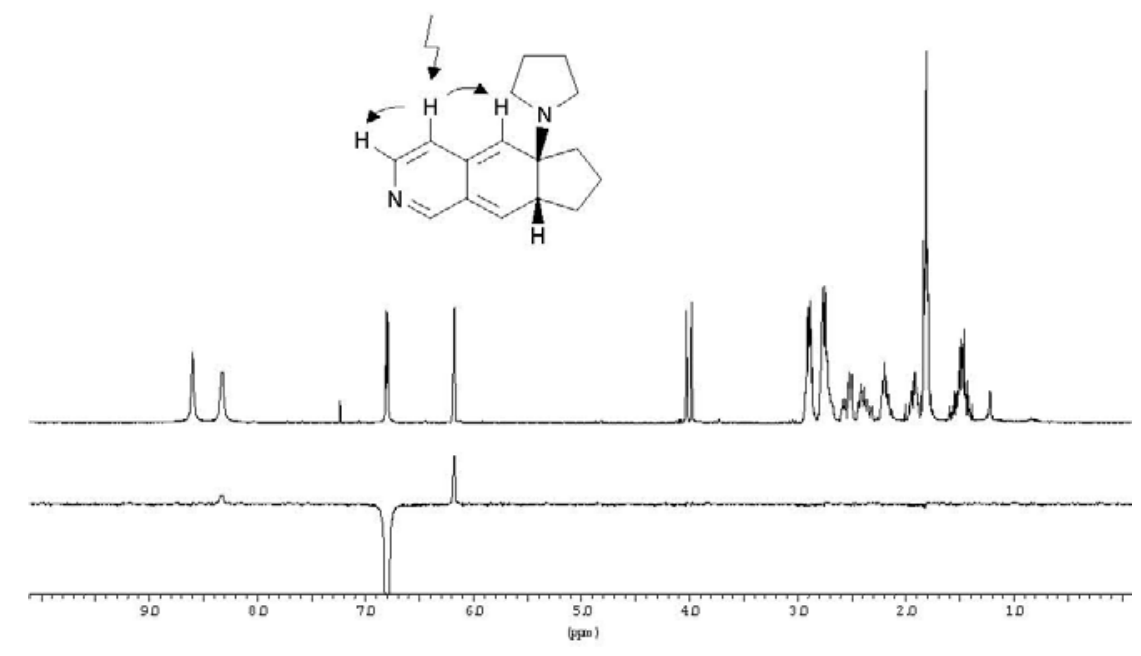

Figure 1. $300 \mathrm{MHz}{ }^{1} \mathrm{H}-\mathrm{NMR}$ Spectrum (upper trace) and NOE difference spectrum (lower trace) of 6,7,8,8a-tetrahydro-5a-pyrrolidino-5aH-cyclopenta $[\mathrm{g}]$ isoquinoline $(\mathbf{A})\left(28^{\circ} \mathrm{C}, \mathrm{CDCl}_{3}\right)$

Saturation of the 4-H resonance leads to difference signals for the adjacent $3-\mathrm{H}(8.32 \mathrm{ppm})$ as well as the olefinic proton at lower field (singlet at $6.18 \mathrm{ppm}, 5-\mathrm{H}$ ) and not for its counterpart at higher field (4.01 ppm, 9-H). The latter signal, however, appears as a doublet because of coupling $(3 \mathrm{~J}=14.1 \mathrm{~Hz}$ ) with the adjacent angular $8 \mathrm{a}-\mathrm{H}$. Thus, the position of the pyrrolidinyl substituent in compound $\mathbf{A}$ must be at 5a-C. Consequently, the structure of the 8a-pyrrolidino isomer has to be assigned to the minor cycloadduct $\mathbf{B}$. This result indicates the preferred regioselectivity of the cycloaddition reaction: the major cycloadduct $\mathbf{A}$ emerged from the interaction of the 1-positions of both pyrido[3,4-d]pyridazine (1) and 1-pyrrolidino-1cyclopentene as shown in Figure 2.
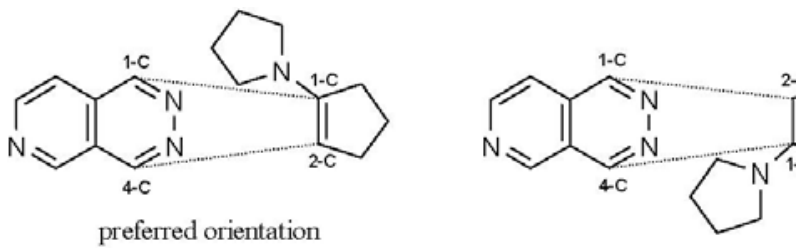

Figure 2

For the observed regioselectivity (ratio $\mathrm{A}: \mathrm{B}=7: 1$, see above), steric factors can be safely excluded because of the symmetrical shape of the azadiene substructure with respect to the approaching dienophile. Thus, the regiochemistry must be primarily governed by the electronic properties of the reactants. In general, the isomer distribution of such [4+2] cycloaddition processes can be understood, based on the magnitudes of frontier orbital coefficients at the atoms involved in the reaction: the preferred orientation is characterized by a combination of "large/large" and "small/small" coefficients at the terminal diene and dienophile atoms. ${ }^{24}$ 
Moreover, some contribution of the corresponding partial charges at the reacting centers has to be considered. In the case of an enamine-type 1-pyrrolidino-1-cyclopentene, the two $\mathrm{sp}^{2}$ hybridized carbon atoms are clearly distinct from each other, with 2-C showing a significantly larger $\mathrm{HOMO} \mathrm{p}_{z}$ orbital coefficient and a more negative partial charge than 1-C. For the azadiene 1 however, the electronic differences between the involved atoms 1-C and 4-C are less striking, as semiempirical calculations revealed: all methods used by us (MNDO, ${ }^{25} \mathrm{AM} 1,{ }^{16} \mathrm{PM} 3,{ }^{26}$ and $\mathrm{SAM}^{27}$ ) indicated a slightly larger LUMO $\mathrm{p}_{z}$ coefficient for 4-C than for 1-C and a slightly more positive partial charge at 4-C; the results are summarized in Table 1. Although these differences of the calculated electronic properties should not be regarded as really significant, the overall tendency with respect to orbital coefficients as well as charge control points into the same direction and, moreover, is in agreement with the experimental results.

Table 1. Calculated LUMO $\mathrm{p}_{z}$ coefficients and partial charges for 1-C and 4-C of $\mathbf{1}$

\begin{tabular}{lllllll}
\hline \multirow{2}{*}{ Method } & $\begin{array}{l}\text { LUMO } \\
1-\mathrm{C}\end{array}$ & $\begin{array}{l}\text { LUMO } \\
\text { 4-C }\end{array}$ & $\begin{array}{l}\text { charge } \\
\text { at 1-C }\end{array}$ & $\begin{array}{l}\text { charge } \\
\text { at 4-C }\end{array}$ & $\begin{array}{l}\text { difference } \\
p_{z}(1)\end{array}$ & $\begin{array}{l}\text { difference } \delta(4)- \\
\delta(1)\end{array}$ \\
\hline MNDO & 0.425 & .432 & +0.0057 & +0.0364 & +0.007 & +0.0307 \\
AM1 & 0.433 & 0.438 & -0.1079 & -0.0838 & +0.005 & +0.0241 \\
PM3 & 0.424 & 0.430 & -0.0811 & -0.0556 & +0.006 & +0.0255 \\
SAM1 & 0.441 & 0.444 & -0.1894 & -0.1782 & +0.003 & +0.0112 \\
\hline
\end{tabular}

\section{Experimental Section}

General Procedures. Melting points were determined on a Kofler hot-stage microscope. IR spectra (KBr pellets) were recorded on a Perkin Elmer 1605 FT-IR instrument. ${ }^{1} \mathrm{H}-\mathrm{NMR}$ spectra were recorded on a Varian Unityplus 300 (300 MHz) spectrometer (TMS as internal reference, values in ppm). HRMS spectra were obtained from a Finnigan MAT 8230 instrument.. For column chromato-graphy Merck Kieselgel 60, 0.063-0.200 mm was used, the medium pressure liquid chromato-graphy (MPLC) was carried out on Merck LiChroprep Si 60, Microanalyses were performed at the Institute of Physical Chemistry (Microanalytical Laboratory), University of Vienna. Pyrido[3,4-d]pyridazine ${ }^{19-21}(\mathbf{1})$ and all enamines ${ }^{28}$ were prepared according to known procedures. For semiempirical calculations the AMPAC software package was employed. ${ }^{29}$

Reaction of pyrido[3,4-d]pyridazine with 1-pyrrolidino-1-cyclopentene. A solution of pyrido[3,4-d]pyridazine (1) (131 mg, $1 \mathrm{mmol}$ ) and 1-pyrrolidino-1-cyclopentene (548 $\mathrm{mg}$, $4 \mathrm{mmol})$ in dry 1,4-dioxane $(10 \mathrm{~mL})$ was refluxed under an Ar atmosphere for $4 \mathrm{~h}$. The volatile components were removed in vacuo, and the residue was purified by column chromatography (ethyl acetate). The oily product obtained upon evaporation of the eluate was either converted into compound 2 (see below) or subjected to MPLC (ethyl acetate) in order to isolate the intermediate. The first fraction contained a mixture $(23 \mathrm{mg})$ of compounds $\mathbf{B}$ and 2 which could not be separated, the second fraction afforded $116 \mathrm{mg}$ (48\%) of 6,7,8,8a-tetrahydro-5apyrrolidino-5aH-cyclopenta[g]isoquinoline (A) as unstable, brownish crystals, mp $82-86{ }^{\circ} \mathrm{C} .{ }^{1} \mathrm{H}-$ 
NMR $\left(\mathrm{CDCl}_{3}\right): \delta 8.60(\mathrm{~s}, 1 \mathrm{H}, 1-\mathrm{H}), 8.32(\mathrm{~d}, J=4.5 \mathrm{~Hz}, 1 \mathrm{H}, 3-\mathrm{H}$; shows positive NOE upon irradiation at $\delta 6.80), 6.80(\mathrm{~d}, J=4.5 \mathrm{~Hz}, 1 \mathrm{H}, 4-\mathrm{H}), 6.18(\mathrm{~d}, J=2.4 \mathrm{~Hz}, 1 \mathrm{H}, 5-\mathrm{H}$; shows positive NOE on irradiation at $\delta 6.80), 4.01(\mathrm{~d}, J=14.1 \mathrm{~Hz}, 1 \mathrm{H}, 9-\mathrm{H}), 2.95-1.40\left(\mathrm{~m}, 15 \mathrm{H}, 7 \mathrm{CH}_{2}, 8 \mathrm{a}-\mathrm{H}\right)$.

7,8-Dihydro-6H-cyclopenta[g]isoquinoline (2). The mixture obtained as described before was dissolved in toluene $(20 \mathrm{~mL})$. After addition of trifluoroacetic acid $(2 \mathrm{~mL})$, the solution was refluxed for $16 \mathrm{~h}$. The volatile components were removed in vacuo, and the residue was dissolved in dichloromethane $(50 \mathrm{~mL})$. The solution was washed with aq. $\mathrm{NaHCO}_{3}$ and water, dried $\left(\mathrm{Na}_{2} \mathrm{SO}_{4}\right)$ and evaporated. The residue was purified by column chromatography (ethyl acetate) to afford 2 (80 mg, 47\%) as almost colorless crystals, mp $108-109{ }^{\circ} \mathrm{C}$ (light petroleum). HRMS calcd. for $\mathrm{C}_{12} \mathrm{H}_{11} \mathrm{~N}$ : 169.0892. Found: 169.0893. ${ }^{1} \mathrm{H}-\mathrm{NMR}\left(\mathrm{CDCl}_{3}\right): \delta 9.07(\mathrm{~s}, 1 \mathrm{H}, 1-\mathrm{H})$, $8.34(\mathrm{~d}, J=5.7 \mathrm{~Hz}, 1 \mathrm{H}, 3-\mathrm{H}), 7.69(\mathrm{~s}, 1 \mathrm{H}, 9-\mathrm{H}$; shows positive NOE upon irradiation at $\delta 9.07)$, 7.55 (s, 1H, 5-H), 7.48 (d, $J=5.7 \mathrm{~Hz}, 1 \mathrm{H}, 4-\mathrm{H}), 3.05-2.95\left(\mathrm{~m}, 4 \mathrm{H}, \mathrm{Ar}-\mathrm{CH}_{2}\right), 2.15-2.00$ (m, 2H, $\mathrm{CH}_{2}$ ). IR: 3056, 3010, 2954, 2916, 2842, 1628, 1586, 1488, 1434, 1410, 1272, 908, $880 \mathrm{~cm}^{-1}$. Anal. calcd. for $\mathrm{C}_{12} \mathrm{H}_{11} \mathrm{~N} \bullet 0.1 \mathrm{H}_{2} \mathrm{O}$ (171.03): C, 84.27; H, 6.60; N, 8.19. Found: C, 84.41; H, 6.66; N, 8.34.

6,7,8,9-Tetrahydrobenzo[g]isoquinoline (3). A solution of pyrido[3,4-d]pyridazine (1) (131 mg, $1 \mathrm{mmol})$ and 1-pyrrolidino-1-cyclohexene (604 mg, $4 \mathrm{mmol})$ in dry 1,4-dioxane $(10 \mathrm{~mL})$ was heated in a closed vessel at $110^{\circ} \mathrm{C}$ under an $\mathrm{Ar}$ atmosphere for $7 \mathrm{~d}$. The volatile components were removed in vacuo and the residue was subjected to column chromatography (ethyl acetate) to afford $3\left(78 \mathrm{mg}, 43 \%\right.$ ) as almost colorless crystals, mp $89-92{ }^{\circ} \mathrm{C}$ (light petroleum). HRMS calcd. for $\mathrm{C}_{13} \mathrm{H}_{13} \mathrm{~N}$ : 183.1048. Found: 183.1037. ${ }^{1} \mathrm{H}-\mathrm{NMR}\left(\mathrm{CDCl}_{3}\right): \delta 9.12(\mathrm{~s}$, $1 \mathrm{H}, 1-\mathrm{H}), 8.40(\mathrm{~d}, J=5.7 \mathrm{~Hz}, 1 \mathrm{H}, 3-\mathrm{H}), 7.66(\mathrm{~s}, 1 \mathrm{H}, 10-\mathrm{H}$; shows positive NOE on irradiation at $9.12 \mathrm{ppm}), 7.53-7.50(\mathrm{~s}+\mathrm{d}, 2 \mathrm{H}, 5-\mathrm{H}, 4-\mathrm{H}), 3.10-2.90\left(\mathrm{~m}, 4 \mathrm{H}, \mathrm{Ar}-\mathrm{CH}_{2}\right), 1.95-1.80(\mathrm{~m}, 4 \mathrm{H}$, $\mathrm{CH}_{2}$ ). IR: 3050, 3018, 2932, 2860, 1632, 1580, 1492, 1432, 1276, 1232, 920, 870, $806 \mathrm{~cm}^{-1}$. Anal. calcd. for $\mathrm{C}_{13} \mathrm{H}_{13} \mathrm{~N} \cdot 0.05 \mathrm{H}_{2} \mathrm{O}$ (184.15): C, 84.79; H, 7.17; N, 7.61. Found: C, 84.77; H, $7.28 ; \mathrm{N}, 7.65$.

7,8,9,10-Tetrahydro-6H-cyclohepta[g]isoquinoline (4). A solution of pyrido[3,4-d]pyridazine (1) $(131 \mathrm{mg}, 1 \mathrm{mmol})$ and 1-pyrrolidino-1-cycloheptene $(660 \mathrm{mg}, 4 \mathrm{mmol})$ in dry 1,4-dioxane $(10 \mathrm{~mL})$ was refluxed under an Ar atmosphere for $30 \mathrm{~min}$. The volatile components were removed in vacuo, and the residue was subjected to column chromato-graphy (ethyl acetate) to afford the 4 (65 mg, 33\%) as almost colorless crystals, mp 138-139 ${ }^{\circ} \mathrm{C}$ (light petroleum). HRMS calcd. for $\mathrm{C}_{14} \mathrm{H}_{15} \mathrm{~N}: 197.1205$. Found: 197.1207. ${ }^{1} \mathrm{H}-\mathrm{NMR}\left(\mathrm{CDCl}_{3}\right): \delta 9.05(\mathrm{~s}, 1 \mathrm{H}, 1-\mathrm{H}), 8.36(\mathrm{~d}, J$ $=6.0 \mathrm{~Hz}, 1 \mathrm{H}, 3-\mathrm{H}), 7.59(\mathrm{~s}, 1 \mathrm{H}, 11-\mathrm{H}$; shows positive NOE on irradiation at $9.05 \mathrm{ppm}), 7.48-$ $7.43(\mathrm{~s}+\mathrm{d}, 2 \mathrm{H}, 5-\mathrm{H}, 4-\mathrm{H}), 2.95-2.85\left(\mathrm{~m}, 4 \mathrm{H}, \mathrm{Ar}-\mathrm{CH}_{2}\right), 1.85-1.70\left(\mathrm{~m}, 2 \mathrm{H}, \mathrm{CH}_{2}\right), 1.70-1.55$ (m, 4H, $\mathrm{CH}_{2}$ ). IR: 3054, 3018, 2924, 2850, 1634, 1586, 1494, 1442, 1352, 1210, 930, 900, $840 \mathrm{~cm}^{-1}$. Anal. calcd. for $\mathrm{C}_{14} \mathrm{H}_{15} \mathrm{~N}$ (197.28): C, 85.24; H, 7.66; N, 7.10. Found: C, 84.94; H, 7.99; N, 7.

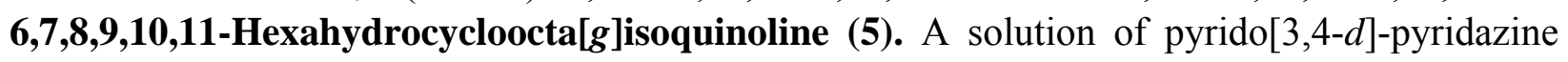
(1) (66 mg, $0.5 \mathrm{mmol}$ ) and 1-pyrrolidino-1-cyclooctene (359 mg, $2 \mathrm{mmol})$ in dry 1,4-dioxane $(5 \mathrm{~mL})$ was heated in a closed vessel at $110{ }^{\circ} \mathrm{C}$ under an $\mathrm{Ar}$ atmosphere for $7 \mathrm{~d}$. The volatile components were removed in vacuo, and the residue was subjected to MPLC (ethyl acetate) to afford the $5(59 \mathrm{mg}, 56 \%)$ as an almost colorless, viscous oil. HRMS calcd for $\mathrm{C}_{15} \mathrm{H}_{17} \mathrm{~N}$ : 211.1361. Found: $211.1368 .{ }^{1} \mathrm{H}$ NMR $\left(\mathrm{CDCl}_{3}\right): \delta 9.15(\mathrm{~s}, 1 \mathrm{H}, 1-\mathrm{H}), 8.42(\mathrm{~d}, J=5.4 \mathrm{~Hz}, 1 \mathrm{H}, 3-$ $\mathrm{H}), 7.69(\mathrm{~s}, 1 \mathrm{H}, 12-\mathrm{H}$; shows positive NOE on irradiation at $9.15 \mathrm{ppm}), 7.56-7.53(\mathrm{~s}+\mathrm{d}, 2 \mathrm{H}, 5-$ 
$\mathrm{H}, 4-\mathrm{H}), 3.00-2.85\left(\mathrm{~m}, 4 \mathrm{H}, \mathrm{Ar}-\mathrm{CH}_{2}\right), 1.85-1.70\left(\mathrm{~m}, 4 \mathrm{H}, \mathrm{CH}_{2}\right), 1.45-1.30\left(\mathrm{~m}, 4 \mathrm{H}, \mathrm{CH}_{2}\right)$. IR: $3052,3002,2916,2850,1632,1580,1494,1448,1356,1278,920,902,884,574 \mathrm{~cm}^{-1}$.

\section{References and Notes}

1. Boger, D. L. Tetrahedron 1983, 39, 2869.

2. Boger, D. L. Chem. Rev. 1986, 86, 781.

3. Boger, D. L.; Weinreb, S. M. Hetero Diels-Alder Methodology in Organic Synthesis; Academic Press: New York, 1987.

4. Marcelis, A. T. M.; van der Plas, H. C. Trends in Heterocyclic Chemistry 1991, 1, 111.

5. Sauer, J. Bull. Soc. Chim. Belg. 1992, 101, 521.

6. Haider, N. Tetrahedron 1991, 47, 3959.

7. Haider, N. Tetrahedron 1992, 48, 7173.

8. Haider, N.; Loll, C. J. Heterocyclic Chem. 1994, 31, 357.

9. Haider, N.; Mereiter, K.; Wanko, R. Heterocycles 1994, 38, 1845.

10. Haider, N.; Wanko, R. Heterocycles 1994, 38, 1805.

11. Haider, N.; Staschek, W. Monatsh. Chem. 1995, 126, 211.

12. Haider, N.; Mereiter, K.; Wanko, R. Heterocycles 1995, 41, 1445.

13. Haider, N. Heterocycles 1995, 41, 2519.

14. Haider, N.; Mavrokordatou, E.; Steinwender, A. Synth. Comm. 1999, 29, 1577.

15. Gruseck, U.; Heuschmann, M. Tetrahedron Lett. 1987, 28, 6027.

16. Dewar, M. J. S.; Zoebisch, E. G.; Healy, E. F.; Stewart, J. J. P. J. Am. Chem. Soc. 1985, 107, 3902.

17. Atfah, M. A. J. Heterocycl. Chem. 1989, 26, 717.

18. Maier, A.; Krauthan, J.; Sauer, J. 16 $6^{\text {th }}$ European Colloquium on Heterocyclic Chemistry, Bled, Slovenia, 1994, Abstr. P-65, 83.

19. Paul, D. B.; Rodda, H. J. Aust. J. Chem. 1968, 21, 1291.

20. Quéguiner, G.; Pastour, P. C. R. Acad. Sci. Ser. C. 1966, 262, 1335.

21. Quéguiner, G.; Pastour, P. Bull. Soc. Chim. Fr. 1969, 2519.

22. Although 7,8-dihydro-6H-cyclopenta[g]isoquinoline (2) is listed in Chemical Abstracts as a known compound, the cited source ${ }^{23}$ does not contain any reference to this molecule.

23. Breault, G. A. Ph. D. Thesis, Brown University, 1987.

24. Fleming, I. Frontier Orbitals and Organic Chemical Reactions; Wiley: London, 1976.

25. Dewar, M. J. S.; Thiel, W. J. Am. Chem. Soc. 1977, 99, 4899.

26. Stewart, J. J. P. J. Comput. Chem. 1989, 10, 209.

27. Dewar, M. J. S.; Jie , C.; Yu, J. Tetrahedron 1993, 49, 5003.

28. Kuehne, M. E. J. Am. Chem. Soc. 1959, 81, 5400.

29. AMPAC 6.02, Semichem Inc., Shawnee, KS 66216, USA 